\title{
The Migration of Technical Workers
}

\author{
Dahl, Michael S.; Sorenson, Olav
}

Published in:

Journal of Urban Economics

DOI (link to publication from Publisher):

doi:10.1016/j.jue.2009.09.009

Publication date:

2010

\section{Document Version}

Publisher's PDF, also known as Version of record

Link to publication from Aalborg University

Citation for published version (APA):

Dahl, M. S., \& Sorenson, O. (2010). The Migration of Technical Workers. Journal of Urban Economics, 67(1), 33-45. https://doi.org/doi:10.1016/j.jue.2009.09.009

\section{General rights}

Copyright and moral rights for the publications made accessible in the public portal are retained by the authors and/or other copyright owners and it is a condition of accessing publications that users recognise and abide by the legal requirements associated with these rights.

- Users may download and print one copy of any publication from the public portal for the purpose of private study or research.

- You may not further distribute the material or use it for any profit-making activity or commercial gain

- You may freely distribute the URL identifying the publication in the public portal -

\section{Take down policy}

If you believe that this document breaches copyright please contact us at vbn@aub.aau.dk providing details, and we will remove access to the work immediately and investigate your claim. 


\title{
The migration of technical workers ${ }^{2}$
}

\author{
Michael S. Dahl ${ }^{\mathrm{a}}$, Olav Sorenson ${ }^{\mathrm{b}, \mathrm{c}, *}$ \\ a Aalborg University, Fibigerstræde 4, DK-9220 Aalborg Ø, Denmark \\ ${ }^{\mathrm{b}}$ University of Toronto, 105 St. George Street, Toronto, ON, Canada M5S $3 E 6$ \\ ${ }^{\text {c }}$ Yale University, 135 Prospect Street, New Haven, CT 06520, United States
}

\section{A R T I C L E I N F O}

\section{Article history:}

Received 1 June 2009

Revised 14 September 2009

Available online 22 September 2009

\section{JEL classification:}

J6

R2

R3

Keywords:

Denmark

Location choice

Revealed preferences

\begin{abstract}
A B S T R A C T
Using panel data on the Danish population, we estimated the revealed preferences of scientists and engineers for the places in which they choose to work. Our results indicate that these technical workers exhibit substantial sensitivity to differences in wages but that they have even stronger preferences for living close to family and friends. The magnitude of these preferences, moreover, suggests that the greater geographic mobility of scientists and engineers, relative to the population as a whole, stems from more pronounced variation across regions in the wages that they can expect. These results remain robust to estimation on a sample of individuals who must select new places of work for reasons unrelated to their preferences-those who had been employed at establishments that discontinued operations.
\end{abstract}

Crown Copyright @ 2009 Published by Elsevier Inc. All rights reserved.

\section{Introduction}

Bureaucrats, politicians and social scientists believe that engineers and scientists play a particularly important role in the economic vitality of the regions in which they work. By stimulating the regional rate of innovation, not only do these individuals create a great deal of value themselves, but also their innovations increase the productivity of others around them (Romer, 1986). As a result, much attention has been given to the movement of these technical workers from one place to another. Some have spun this migration in a positive light, focusing on the contributions of these individuals to the places that receive them. Foreign-born scientists, for example, account for a substantial share of the academics in the United States, and an even larger proportion of the prominent ones (Levin and Stephan, 1999; Stephan and Levin, 2001). Others have pointed to its potential downside for the regions losing this valuable human capital, the so-called "brain drain" (Bhagwati and Hamada, 1974; Galor and Tsiddon, 1997).

\footnotetext{
Financial support from the Rockwool Foundation and the Social Science and Humanities Research Council of Canada (Grant \# 410-2007-0920) made this research possible. We also thank Stuart Rosenthal, Albert Saiz, and participants in the NBER Cities and Entrepreneurship Conference for their useful comments on an earlier draft of this paper.

* Corresponding author. Address: University of Toronto, 105 St. George Street, Toronto, ON, Canada M5S 3E6.

E-mail address: olav.sorenson@rotman.utoronto.ca (O. Sorenson).
}

Despite this interest and the importance of these individuals to the economy, social scientists have a relatively limited understanding of why these individuals move. Most research to date has focused on the flows of professionals, scientists and engineers across countries. Though these individuals appear more mobile than the general population (Dumont and Lemaitre, 2005), several factors might account for this pattern. For example, the highly educated may have more to gain economically from moving than their compatriots with less human capital. Or, they may place less value on remaining proximate to family and friends. But these patterns might also simply reflect immigration policy. Countries, particularly in the latter half of the twentieth century, have been more welcoming of educated immigrants. Even if technical and nontechnical workers had similar interests in moving, these policies could still produce higher observed rates of international migration among the well educated.

To learn more about the individual-level factors underlying the geographic mobility of technical workers, we focus on the withincountry migration of these individuals. Within-country moves should also reflect the preferences that people place on the possibility of earning higher income versus the value of remaining close to family and friends. They have the advantage, however, of not being distorted by immigration policies. The intra-country mobility of scientists and engineers also deserves attention in its own right. To the extent that the spillovers generated by these individuals occur at a more local level than the nation as a whole (Rosenthal and Strange, 2008), understanding scientists and engi- 
neers' decisions about where to work within a country can improve our understanding of why some regions grow while others stagnate.

To examine this within-country migration of technical workers, we analyzed data from Denmark. Though a small country, the Danish labor market exhibits similar levels of both organizational and geographic mobility to the United States (Sorensen and Sorenson, 2007; Dahl and Sorenson, 2008). ${ }^{1}$ We therefore have no reason to believe that the results might not extrapolate to other populations. The Danish data, moreover, have two central advantages over comparable data from the United States, the most commonly studied country. First, they include detailed information on education for every employee in Denmark, enabling the construction of counterfactual incomes for the amount that technical workers could expect to earn elsewhere. Second, they contain links from individuals to their families and to their specific educational institutions, allowing us to calculate distances from places to family and friends (classmates).

We estimated models of where those trained in science and engineering chose to work in 2006. Our analysis focused on these decisions among two samples of those educated in science and engineering: (i) a random sample of those working anywhere in 2005 and (ii) all those employed in 2004 at workplaces that closed in 2004 or employed in 2005 at workplaces that closed in 2005. The latter sample addresses the fact that individuals may vary (endogenously) in their propensities to consider changes in employment. We found that technical workers value (in order from most to least important in the second sample): (i) proximity to their current homes, (ii) proximity to parents, (iii) high school classmates in the region, (iv) college classmates in the region, (v) proximity to places they have lived in the past 25 years, and (vi) income. Though this preference ordering appears fairly consistent across age cohorts, older individuals value income more highly relative to social factors than younger ones. The magnitudes of these preferences for proximity to friends and family, moreover, are large. For example, the average Danish scientist or engineer would tradeoff \$1299 in annual income for each college classmate in the region.

We also examined the location choices of couples, where both individuals are scientists or engineers. Although it has been suggested that the increasing concentration of such highly educated couples in cities may stem from the constraints associated with maximizing their joint earnings (Costa and Kahn, 2000), we found no evidence that these Danish "power" couples placed heavier weights than individuals on working in more densely populated regions relative to other factors. Couples did, however, place greater importance on being proximate to parents, perhaps because they provide supplemental childcare.

We believe that the paper offers several contributions. First, it offers an approach for estimating the revealed preferences of individuals for trading off income versus other factors in their choices of where to work. Prior research has typically focused on either economic or social factors in location choice, but not on both simultaneously (Dahl and Sorenson, 2008). Second, it provides a rare look at the within-country geography and migration of scientists and engineers. Even within Denmark, one sees substantial net migrations of technical workers from some regions to others. But the pattern is far from simple. Neither differences in income nor in population can adequately explain these flows. Third, it documents the fact that these individuals place a high value on locating close to family and friends. That fact has important implications for the geographic distribution of skilled labor, return migration, and the persistence of economic inequality across regions.

\footnotetext{
${ }^{1}$ Because of its size, one can only compare geographic mobility in Denmark to within-state movements in the United States. A move of the distance of Los Angeles to New York would land a Dane in Dubai.
}

\section{Inter-regional migration}

Although migration research has examined the flows of people both across and within countries, studies specific to the geographic mobility of scientists and engineers have been almost exclusive in their focus on the international movements of these individuals. We nevertheless see the intra-country movements of scientists and engineers as an equally important topic for at least three reasons. First, just as a brain drain may handicap the economic growth of developing nations, the movement of scientists and engineers from some regions to others within a country could exacerbate, rather than dampen, within-country inequalities. Second, to the extent that these relocations facilitate agglomeration externalities or the better matching of employees to employers, the mobility of the highly skilled may influence the overall productivity of nations. Third, by studying migration in a setting free from the influence of immigration policies and linguistic differences, the examination of these within-country moves provides a better understanding of how individual preferences influence geographic mobility.

Our analysis here focuses on the within-country movement of scientists and engineers in Denmark using the Integrated Database for Labor Market Research (referred to by its Danish acronym, IDA) maintained by Statistics Denmark. Although ideally one might want to explore the location choices of technical workers in a larger country, such as the United States, the Danish data offer several advantages that counterbalance the potential limited generalizability of focusing on such a small country: The IDA database, for example, allows researchers to distinguish between earned and unearned income, to track all residents of Denmark for 26 years, to identify the educational degrees that they earned, and to link individuals to their parents, siblings and high school and college classmates.

We identified (potential) technical workers through their educations. In particular, we considered someone a technical worker if they received a postgraduate degree in a biological or physical science, engineering or medicine (regardless of whether they needed such an educational credential for their current job). Alternatively, one could use occupational codes to identify those employed in technical jobs. Such an approach would nevertheless have two critical disadvantages. First, individuals with identical educations and engaged in similar activities can hold a variety of job titles. An engineer, for example, might have the job of professor, supervisor or consultant. Second, and probably more important, an individual's occupation may depend on the availability of employers in a region. Such an approach, therefore, could lead to the unpalatable consequence that a person's status as a technical worker could depend on where he or she chose to work.

\subsection{The geography of technical employment}

Fig. 1 depicts the concentration of those educated as scientists and engineers per thousand employees in 2006. Each delineated boundary outlines a township (kommune in Danish). Note that the regions in the top quartile have at least twice the density of technical workers as those in the bottom. In terms of situating these regions relative to specific places, the densest concentrations on this map appear in and around Copenhagen, Århus, Odense and Aalborg - the four largest cities in Denmark, all home to large universities - but many smaller towns, such as Kalundborg, Nordborg, Holeby, Tjele and Bjerringbro, show similarly high concentrations of these workers.

\subsection{The mobility of scientists and engineers}

Although scientists and engineers concentrate in some regions, this agglomeration does not necessarily imply geographic mobility. 


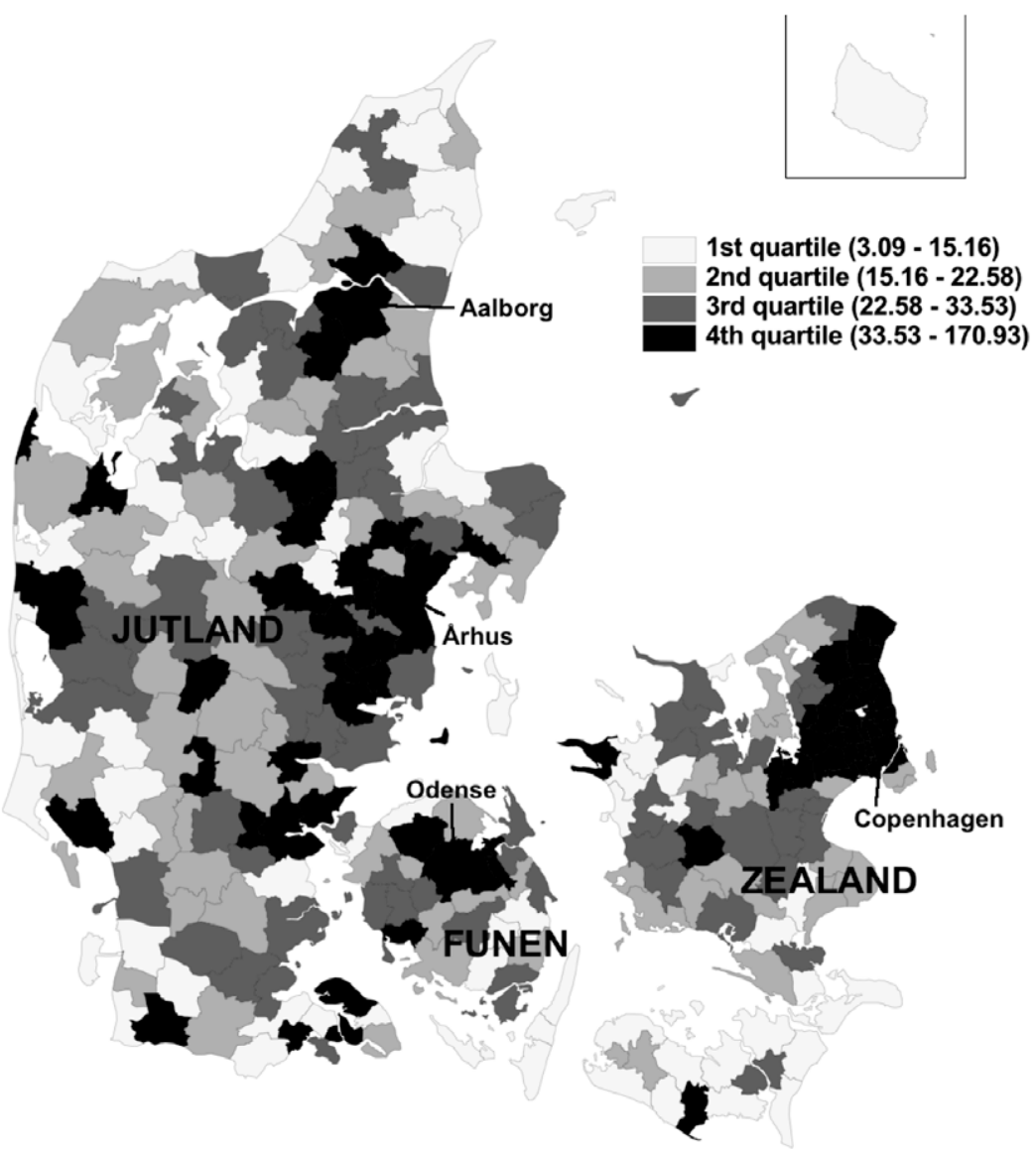

Fig. 1. Danish townships (kommuner) shaded by technical workers per 1000 .

As noted above, some of the places with the densest concentrations of technical workers also have large universities. Those receiving degrees from these institutions might simply stay in the surrounding area. One must therefore consider not just the stocks of individuals by region but also their flows.

Fig. 2 examines the migration of scientists and engineers by mapping the source and sink regions for those educated in science, engineering and medicine. Townships have been shaded according to the net migration of technical workers per 1000 employees into and out of the regions in which they received their high school educations. Those townships shaded in solids received more scientists and engineers than they lost. Those shaded with stripes, meanwhile, experienced an exodus of technical workers. Unshaded regions may have had migration, but with balanced inflows and outflows. Most of the regions gaining scientists and engineers appear to border either the east coast of Jutland, the west or east coast of Funen, or the north or south coast of Zealand. Interestingly, a comparison of this map to Fig. 1 reveals that many of the regions with the greatest gains in technical workers do not have the highest current concentrations of those employees.

One can also examine migration at the level of the individual. Here, we find it instructive to compare the geographic mobility of scientists and engineers to non-technical workers. Fig. 3 graphs the kernel density estimates of the distribution of the distance between where individuals worked in 2005 and where they worked in 2006 (the dark line represents technical workers while the light line denotes non-technical workers). Although the lines look quite similar, technical workers move far more often than non-technical workers. However, among both technical and non-technical workers, most individuals stayed employed in the same place-often with the same employer. The masses of the probability distribu- tions, moreover, drop rapidly from a distance of zero to roughly $10 \mathrm{~km}$. Beyond that point, the distributions flatten out. If one must move residences, it appears that the distance of that move may not matter much. ${ }^{2}$

By comparison, the United States Census Bureau reports that $14.4 \%$ of Americans between the ages of 18 and 64 moved residences between 2006 and 2007. ${ }^{3}$ Of these, 64\% moved within the same county (i.e. moved less than $34 \mathrm{~km}$ on average). Only $5.1 \%$ of Americans moved to another county in that year, a rate quite comparable to the proportion of moves over $35 \mathrm{~km}$ in the Danish population.

\subsection{The geography of economic opportunity}

What might explain these differences? The literature on the international flows on scientists and engineers has primarily focused on two mechanisms. The first is migration to escape persecution or repression. In the 1930s, for example, the Nazis dismissed thousands of academics from their posts in Germany, most of whom then moved to institutions in England or the United States (Medawar and Pyke, 2001). This explanation, however, has little to say about the within-country movements of technical workers. The second mechanism is the lure of more attractive economic

\footnotetext{
${ }^{2}$ Few individuals in Denmark commute more than $10 \mathrm{~km}$. Larger distances between old and new workplaces therefore often entail a change in residence as well as of employer.

${ }^{3}$ Although one could perhaps calculate it, given access to the Integrated Public Use Microdata, the Census Bureau does not currently disaggregate the geographic mobility of residents into an occupational category that corresponds to technical workers.
} 


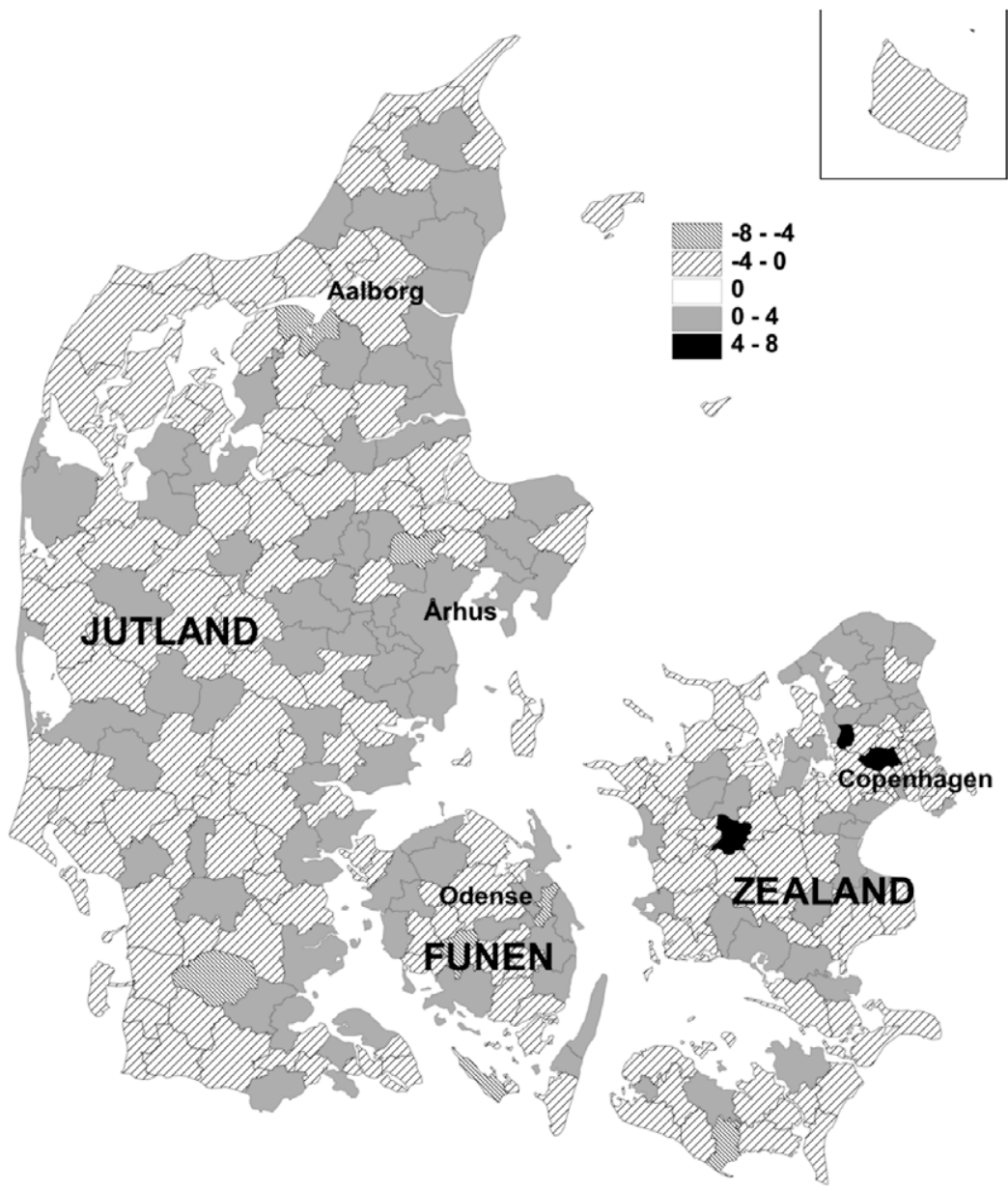

Fig. 2. Danish townships shaded by net technical worker migration per 1000 .

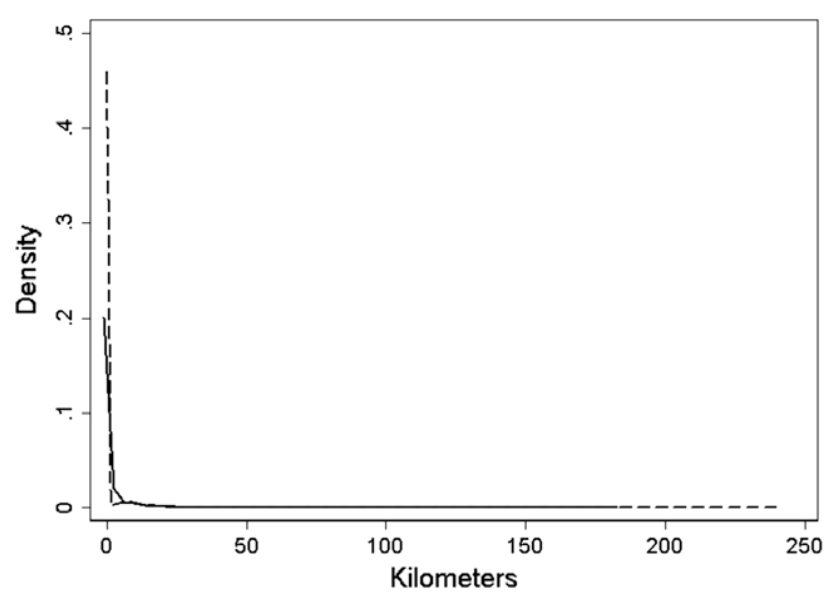

Fig. 3. Kernel density estimates of the distance between individuals' 2005 and 2006 workplaces (dashed line denotes non-technical workers; solid line represents scientists and engineers).

opportunities. Concerns about brain drains have primarily been in terms of scientists, engineers and professionals leaving less developed countries for places like Canada and the United States, where they can earn far more. But even within countries technical workers may have much to gain by moving.

To explore how income differentials might influence withincountry migration, Fig. 4 shades each region (kommune) according to its average income per employed person, in 2006, in kroner per year. Using the average exchange rate for 2006 of 5.94 kroner per dollar, these income categories convert to: $\$ 36,601-43,166$; $\$ 43,167-45,127 ; \$ 45,128-47,687$; and $\$ 47,688-63,914$. Perhaps not surprisingly, the same regions with the densest concentrations of technical workers also generally had the highest average incomes.

But this variation in average income does not necessarily mean that scientists and engineers earned more in these regions. It could instead reflect compositional differences in the people employed there or in the kinds of work they do (Combes et al., 2008). Most obviously, these averages include the incomes of technical workers themselves, who tend to earn more than the median employee. To address these issues, Fig. 5 shades regions according to the average incomes of the technically educated working in those regions. Again, converting these average income quartiles to dollars yields: $\$ 43,584-65,324$; $\$ 65,325-71,157 ; \$ 71,158-74,797$; and $\$ 74,798-$ 91,363 . Although technical workers tend to earn more in the regions in which they reside in the highest concentrations, the relationship appears less tightly correlated in this picture.

\section{Determinants of migration}

Though suggestive, these aggregate patterns nonetheless reveal little about why workers move from one place to another (and even less about who moves). We therefore turn to an individual-level estimation of the determinants of work location choice.

\subsection{Samples}

Although we have panel data, our analysis focused on where individuals with degrees in science and engineering chose to work 


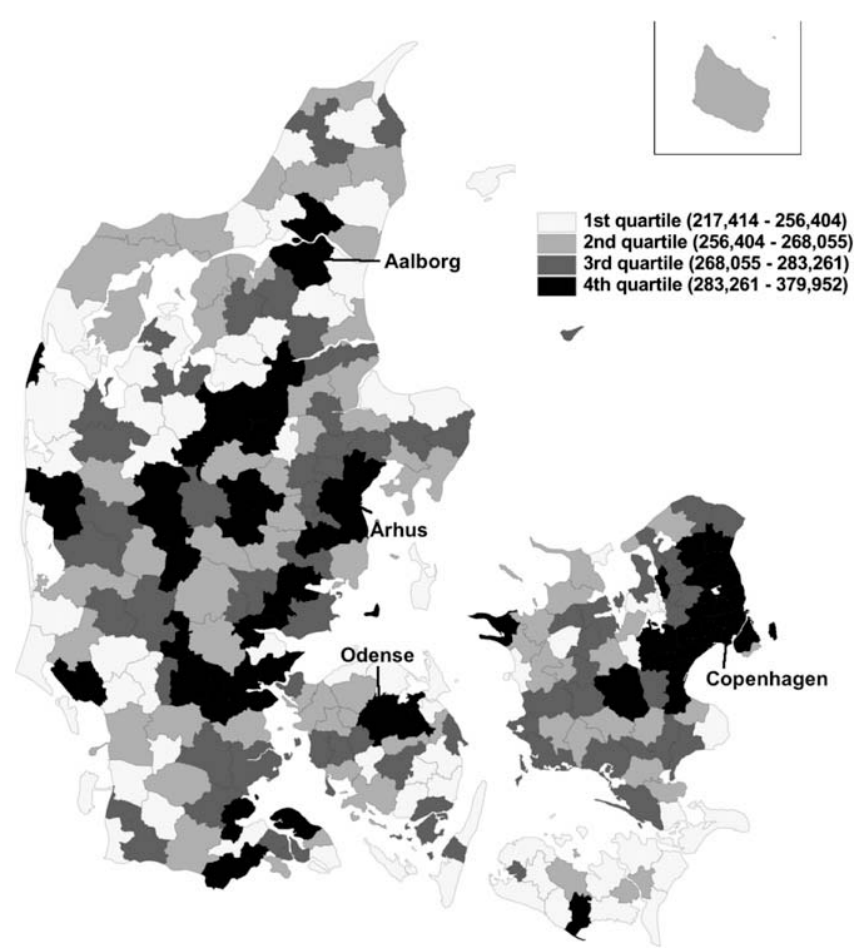

Fig. 4. Danish townships shaded by average income.

in 2006 on the basis of the attributes of those individuals and regions in 2005 (or, in some cases, where they chose to work in 2005 on the basis of 2004 attributes). We estimated our models on three separate samples. In all three cases, we excluded all individuals under 18 and over 42 . Those under 18 often move with their parents, and we could not track those over 42 to their hometowns because they left secondary school before the beginning of the IDA data.

From the 40,231 individuals that met these criteria in 2005, we extracted two samples (of identical size to ease comparisons across the samples): (1) a simple random sample of 7500 individuals; (2) a random sample of 7500 individuals that changed employers from 2005 to 2006 (99.6\% of the 7533 eligible). Although the simple random sample might appear the obvious one, we explored this second sample for a variety of reasons. Most importantly, our estimation essentially assumes that individuals consider the available alternatives each year and decide whether or not to continue in their current jobs and regions. Once a job has been found, however, many individuals may not consider alternatives unless they become dissatisfied with their employers (Vroom, 1964). As a result, the simple random sample may provide biased estimates of the relative weightings that individuals place on various factors when actively choosing a job.

A logical alternative is to include only those who changed employers, but not necessarily their region of employment (our second sample). Among these individuals, the assumption of an active choice seems more valid. This sample nevertheless has its own weaknesses, most notably, it selects on the dependent variable. A whole host of people may have considered alternatives to their current employers and decided not to switch. The movers therefore may represent only those cases on the margin, in which the benefits to moving exceeded the costs, either because they had much to gain by moving or because they placed unusually low weights on other features of the region.

To address this potential endogeneity in the decision to change employers, we considered a third sample of individuals that had to find jobs (for reasons unrelated to their preferences or personal

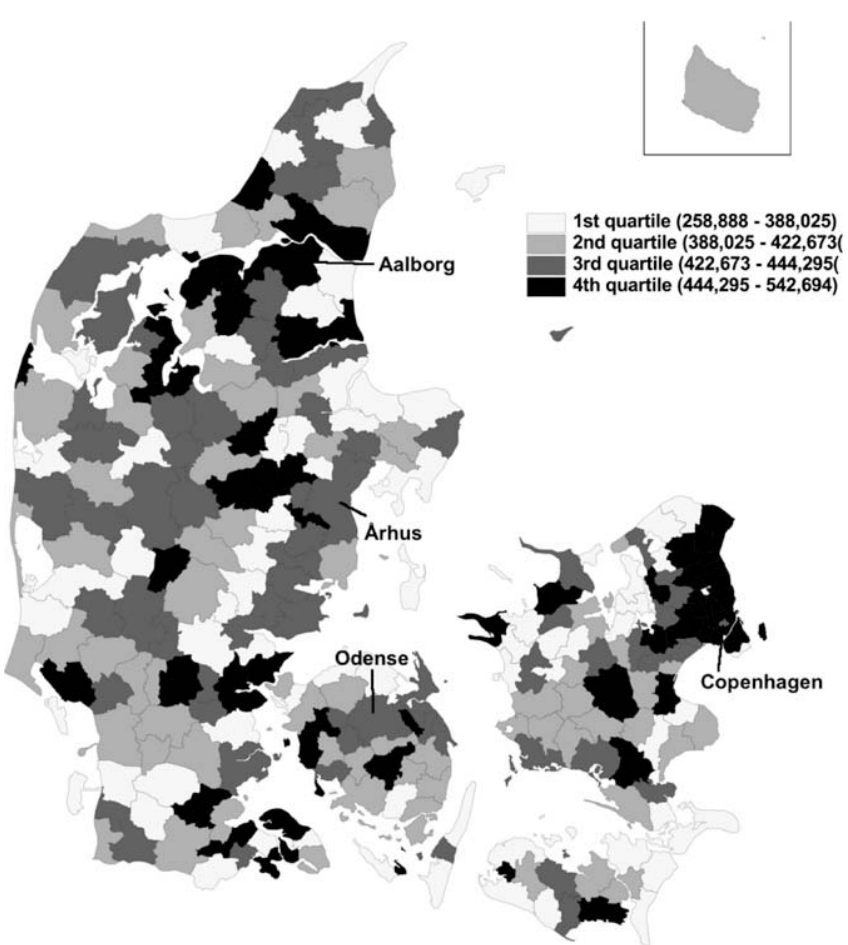

Fig. 5. Danish townships shaded by average technical worker income.

performance on the job): those employed at establishments that closed. Because only a small proportion of technical workers find themselves in such a situation (fewer than 1000 in 2005), we aggregated two years of data for this sample, combining those employed at establishments that closed in either 2004 or 2005 $(N=1939)$. For the 2004 set, we calculated the covariates using data from 2004 and predicted the places of employment in 2005. For the 2005 set, the information from 2005 predicts choice in 2006. Because the closure of these places of business probably had little to do with the turnover of any one individual, we can consider the decision to move in this sample exogenous to the attributes of individuals and their preferences across regions. ${ }^{4}$ This third sample should therefore offer the most valid estimates of the weights that individuals place on various factors when actively choosing locations, though the involuntary loss of employment could lead individuals in this group to value more highly the social support of family and friends.

\subsection{Estimation}

We adopted a standard choice modeling approach, assuming that individuals compare the pros and cons of potential places of employment, weight these factors according to their personal preferences and then (stochastically) choose the ones that maximize their expected satisfaction (utility). Under these assumptions, one can write the utility that an individual $i$ would receive from working in a particular region, $j$, as:

$u_{i j}=\beta^{\prime} x_{i j}+\epsilon_{i j}$,

\footnotetext{
${ }^{4}$ The average plant closing event resulted in the displacement of 2.9 technical workers, though it usually displaced a much larger number of non-technical workers. On average, those laid off accounted for less than $4 \%$ of the labor force of scientists and engineers in a region. As a robustness check, we re-estimated the results excluding closings that affected more than $10 \%$ of the technical labor force and found substantively equivalent results.
} 
where $x_{i j}$ denotes a vector of region-specific attributes for individual $i$ (e.g., wage or distance to college classmates), $\beta$ indicates a vector of weights that the individual places on each of those attributes, and $\epsilon_{i j}$ allows for error in individuals' evaluations of the utility that they would receive from working in region $j^{5}$

If individuals choose to work in the regions that maximize their expected utilities and if the errors $\left(\epsilon_{i j}\right)$ come from independent and identically distributed draws from an extreme value distribution (Type 1 ), then the probability that individual $i$ chooses region $j$ is:

$P\left(y_{i}=j\right)=\frac{e^{\beta^{\prime} x_{i j}}}{\sum_{J} e^{\beta^{\prime} x_{i j}}}$

We can estimate (2) and the weights for the regional characteristics with the conditional logit (McFadden, 1974). Using this approach, one can assess the relative importance of various attributes to technical workers' decisions of where to work.

In choosing an areal unit of analysis, for $j$, we used the smallest unit available to provide the finest-grain variation possible in our measures of regional attributes. From 2004 to 2006, Denmark comprised 271 mutually exclusive and exhaustive administrative townships (kommune in Danish). ${ }^{6}$ But we did not consider all of these townships possible destination states for each individual. We only considered a region at risk of being chosen if another individual with the same (five-digit) educational background as individual $i$ worked in the labor market to which region $j$ belonged in 2005 (or 2004). At the five-digit level, these educational codes distinguish both across levels (Ph.D./M.A.) and subdisciplines. For example, engineering includes distinct five-digit codes for electrical and mechanical engineering, construction management, architecture, and surveying. As a result, each individual, on average, chose from among 199 townships.

Our models included fixed effects for each of the 77 labor markets in Denmark. These fixed effects should capture at least three important factors. First, they should purge from the estimates any unusual effects that the large cities might have in attracting technical workers. Second, they adjust for differences across regions in the cost of living. Third, they should also control for variation in the amenities that these regions offer (Glaeser et al., 2001). Although weather does not differ greatly across Denmark, regions do vary considerably in the cultural activities available in them. We nonetheless note that (unreported) models without these fixed effects produced very similar results. Though these factors matter to location choice, their influence appears relatively orthogonal to variation in income and the locations of family and friends.

\subsection{Covariates}

We considered both economic and social factors as predictors of location choice. As noted above, the most prominent factor used to describe why scientists and engineers - and all people more generally - move from one place to another is the search for better employment opportunities. Studies have consistently found that expected wages strongly predict migration (e.g., Davies et al., 2001; Scott et al., 2005). But the literature also suggests that family and friends act as anchors in this process, keeping individuals moored in place. Research, for example, has found that people move far less (and shorter distances) than one would expect on purely economic grounds (Sjaastad, 1962). Immigrants have a high probability of returning to their home countries, a pattern called

\footnotetext{
${ }^{5}$ Our initial models assume that all individuals apply the same weights to all factors, but we relax this assumption below by allowing for heterogeneity in the weight coefficients.

6 We excluded the island of Christiansø, which has fewer than 100 residents, from our analysis.
}

return migration, even when their regions of origin remain economically far behind (for a review, see Gmelch, 1980). Research on entrepreneurs, meanwhile, has found that they exhibit a strong propensity to remain near to their home regions even when other places appear to offer more attractive economic climates for their ventures (Figueiredo et al., 2002; Dahl and Sorenson, 2009). We calculate a variety of variables to capture these economic and social factors.

\subsubsection{Expected income}

Past studies have typically used the average wage, or qualityadjusted average wage, in a region as a proxy for the income that an individual might expect from moving there. Relying on population average wages as a proxy nevertheless raises a number of issues. Regions differ in human capital and industrial bases (Combes et al., 2008). As a consequence, the average wage in a region might have little to do with what a specific individual could expect to earn. Todaro (1969), for instance, discusses the fact that, though urban areas have much higher average wages than rural ones, an experienced farmhand might nonetheless expect lower wages in the city, given the mismatch of his skills to the needs of local employers.

Dahl and Sorenson (2008) proposed an alternative approach. They estimated wage equations for each region, essentially allowing the returns to various individual characteristics to vary by location. Those estimates then allowed them to calculate individualspecific counterfactual wages for each location a person might choose. Such an approach, however, is not as useful for scientists and engineers, who have highly specific training. One year of education in electrical engineering, for example, may have a very different value from one year of education in medicine, even within the same region.

To address these issues, our measure of the income that an individual could expect in another region averages the logged incomes of all of those in the labor market with the same five-digit education. As noted above, these five digits identify an education of a particular level in a specific subfield (e.g., a doctoral degree in electrical engineering). We used the 77 labor markets in Denmark instead of the townships (kommune) to construct these averages for two reasons: First, it allows us to average over a larger number of individuals and therefore to reduce the influence of idiosyncratic income differences as a source of measurement error. At this level of aggregation, our expected income measure comes from an average of roughly 20 individual incomes in the typical region. Second, it accounts for the fact that individuals might commute to their jobs. In essence, this measure captures what someone with the same educational credentials would earn in a region. If no employers can fully use that education, it should capture the next best alternative available. Note that, because of the labor market fixed effects, our identification for the importance of income comes entirely from within-region variation in the returns to different kinds of education (i.e. differences across labor markets in the average wages that they offer have been netted out).

We also assigned this expected income as the amount that individuals could expect to receive if they remained in their current jobs. Alternatively, one might substitute their actual income for what they could expect if they did not move, but that has at least one drawback: Actual income captures returns to both education and other individual characteristics, while our expected income measure depends only on education. Mixing the two could potentially bias the comparisons of the current place of employment to others.

\subsubsection{Distance to home}

We calculated the logged distance in kilometers between each person's home address in 2005 (or 2004) and the centroid of each 
township to which the individual might move (or stay) in 2006 (or 2005). Although this variable, in part, captures an individual's interest in staying close to extended family, friends and colleagues, it might also capture a number of non-social factors, such as the direct costs of commuting or moving, or the anchoring effect of owning a home (Coulson and Fisher, 2009).

\subsubsection{Distance to parents}

We located both parents of each individual and included an indicator variable denoting their location(s) in 2005 (or 2004). We then calculated the logged distance in kilometers from each township to these locations. If the parents lived at different addresses, we averaged the distance from the township to each parent.

\subsubsection{Distance to siblings}

We constructed a parallel measure for siblings. Our measure includes half-siblings because we identified siblings as all individuals that shared at least one parent with the focal individual. Once again, our measure averaged the logged distance in kilometers from these individuals' home addresses in 2005 (or 2004) to the centroid of each township in cases with more than one sibling.

\subsubsection{Distance to home town}

We also attempted to identify each person's hometown(ship). Although we could not track where a person lived for the entire duration of his or her childhood, we could determine the secondary school from which he or she graduated. We therefore calculated this measure as the logged distance in kilometers from the location of their secondary schools to the centroid of each township.

\subsubsection{Distance to prior residences}

Since people also probably form relationships in every place in which they have lived, we constructed another measure of past location. We first identified every place that the individual had lived since 1980 . We then calculated and averaged the logged distance between each of these locations and every township. ${ }^{7}$

\subsubsection{High school classmates in region}

Although we could not survey individuals directly to identify their friendships, we could use the census data to create a measure of the locations of individuals with a high probability of being friends. In particular, we constructed a measure of prior migration flows by high school classmates, counting the number of members of one's high school class that lived in each township in 2005 (or 2004).

Because it uses past flows to predict future flows, this measure of prior mobility has the potential to confound social preferences for unobserved factors affecting migration. To mitigate this problem, we included a control for the movement of individuals from other cohorts-in this case, the class that graduated the year before and the one that graduated the year after the focal individual (labeled other high school classes in region in the tables). This control should absorb any stable unobserved factors that commonly affect individuals from that high school, leaving the measure of classmates to capture the draw of friends.

\footnotetext{
7 Since friendships within a region form over time, one would expect the intensity of attachment to a region to increase with the time lived there but to fade after emigration. We therefore experimented with weighting regions according to the time lived there (and the recency of residency). Both of these adjustments incrementally improved the fit, but we report this simpler specification in the interest of easy interpretation and comparison.
}

\subsubsection{College classmates in region}

Using the same approach, we also constructed a measure of the number of college classmates in each township, as well as another control for unobserved heterogeneity, other college classes in region.

\subsubsection{Region size}

We measured population in terms of the logged number of employees in the township. The labor market fixed effects nevertheless induce a mechanical relationship between this variable and location choice-the areas within labor markets with more employees are the areas where businesses are. The estimates from these models, therefore, probably overrate the attractiveness of urban regions. Indeed, estimates without the fixed effects yielded coefficient sizes roughly $30 \%$ smaller than those with them.

\subsubsection{Work region}

Finally, we created an indicator variable for the township of an individual's employment in 2005 (or 2004). This variable should help to account for the fact that many people may not actively consider alternative jobs each year and therefore remain employed in the same township. Descriptive statistics for these variables appear in Table 1.

\section{Results}

Table 2 reports the results of our first set of models. Across all three samples, both economic and social factors influence individuals' choices of where to work. As we move from the simple random sample (model 1) to the sample of those changing employers (model 2), we note two main differences. ${ }^{8}$ First, the job changers exhibited a lower likelihood of staying in the same region (captured in the work region variable). Given that the sample selects on movers, that result seems unsurprising. Second, the job changers appear more sensitive to expected income, relative to social factors, in their choices of locations than the population as a whole. Again, hardly surprising, given that these individuals have actively considered a change of jobs. The other factors, however, differ little in their estimated importance across the two groups.

By contrast, the sample of individuals employed at establishments that closed (model 3) differed in two ways from both the random sample and from job changers: First, relative to proximity to family and friends, this group placed greater weight, on average, on expected income. Second, proximity to parents also influenced their choices more heavily than propinquity to other family and friends. This sample did not, however, assign higher weights to all social factors-as one might have anticipated if the unexpectedly unemployed relied more on social support. Though the estimates do not differ dramatically, we nonetheless focus from here forward on the results of the sample of those employed in 2004 or 2005 at establishments that closed, those choosing for the most plausibly exogenous reasons.

In model 3, many factors significantly predicted where scientists and engineers chose to work. The more interesting information, therefore, regards the relative magnitudes of these coefficients. In interpreting these magnitudes, we find it useful to convert the coefficients into dollar equivalents. ${ }^{9}$ We do so by calculating the point at which the average individual would consider the

\footnotetext{
8 Note that one cannot compare the absolute size of the conditional logit coefficients across samples directly because the marginal effect of a variable depends on the levels of all of the other variables. In particular, $\Delta P_{j} / \Delta x_{j}=P_{j}\left(1-P_{j}\right) \beta_{x}$, where $P_{j}$ denotes the probability of choosing region $j$ given the full vector of region attributes. Our discussion therefore focuses on the relative size of the effects associated with various factors.

${ }^{9}$ We converted the values from Danish kroner to U.S. dollars using the average exchange rate for 2006: $5.94 \mathrm{DKK}=\$ 1$.
} 
Table 1

Descriptive statistics for the choice locations.

\begin{tabular}{|c|c|c|c|c|c|c|}
\hline \multirow[t]{2}{*}{ Variable } & \multicolumn{2}{|c|}{ Random sample } & \multicolumn{2}{|c|}{ Employer change } & \multicolumn{2}{|c|}{ Workplace closings } \\
\hline & Mean & SD & Mean & SD & Mean & SD \\
\hline Expected Ln (income) & 13.00 & 0.147 & 13.00 & 0.145 & 12.99 & 0.144 \\
\hline Ln (distance to home) & 1.794 & 1.311 & 1.960 & 1.410 & 1.832 & 1.400 \\
\hline Ln (distance to parents) & 0.312 & 0.996 & 1.554 & 1.77 & 1.997 & 1.785 \\
\hline Ln (distance to siblings) & 0.339 & 1.061 & 1.662 & 1.835 & 1.796 & 1.879 \\
\hline Ln (distance to hometown) & 0.446 & 1.192 & 2.240 & 1.815 & 1.105 & 1.711 \\
\hline Ln (distance to prior residences) & 0.381 & 0.957 & 1.949 & 1.409 & 0.914 & 1.345 \\
\hline High school classmates in region & 18.62 & 59.59 & 17.67 & 58.45 & 25.367 & 76.67 \\
\hline Other high school classes in region & 36.17 & 115.5 & 34.41 & 114.2 & 48.90 & 146.2 \\
\hline College classmates in region & 6.825 & 13.79 & 6.805 & 14.81 & 7.189 & 15.41 \\
\hline Other college classes in region & 13.13 & 26.00 & 12.86 & 27.50 & 14.31 & 30.15 \\
\hline Work region & 0.852 & 0.355 & 0.291 & 0.454 & 0.563 & 0.496 \\
\hline Ln (region size) & 10.29 & 1.398 & 10.38 & 1.383 & 10.64 & 1.463 \\
\hline$N$ & 7500 & & 7500 & & 1939 & \\
\hline
\end{tabular}

Table 2

Conditional logit estimates on location choice.

\begin{tabular}{|c|c|c|c|c|c|c|}
\hline \multirow[b]{2}{*}{ Expected Ln (income) } & Random sample & & \multicolumn{2}{|c|}{ Employer change } & \multicolumn{2}{|c|}{ (3) } \\
\hline & $0.469_{* * *}^{* *}$ & $(0.160)$ & $0.898_{* * *}^{* *}$ & $(0.102)$ & $1.006_{* *}^{* *}$ & $(0.218)$ \\
\hline Ln (distance to home) & $-0.798^{* *}$ & $(0.022)$ & $-0.756_{* *}^{* *}$ & $(0.013)$ & $-0.668_{* *}^{* *}$ & $(0.029)$ \\
\hline Ln (distance to parents) & -0.004 & $(0.120)$ & $-0.095_{*}^{*}$ & $(0.024)$ & $-0.249^{* *}$ & $(0.048)$ \\
\hline Ln (distance to siblings) & -0.032 & $(0.092)$ & $-0.044_{* *}^{*}$ & $(0.019)$ & -0.059 & $(0.044)$ \\
\hline Ln (distance to hometown) & -0.145 & $(0.102)$ & $-0.181_{* *}^{* *}$ & $(0.022)$ & $0.025_{*}$ & $(0.075)$ \\
\hline Ln (distance to prior residences) & -0.109 & $(0.093)$ & $-0.219^{* *}$ & $(0.030)$ & $-0.193^{*}$ & $(0.079)$ \\
\hline High school classmates in region & $0.006^{\dagger}$ & $(0.003)$ & $0.004 \dagger_{* *}^{+}$ & $(0.002)$ & 0.005 & $(0.004)$ \\
\hline Other high school classes in region & $-0.003 \dagger$ & $(0.002)$ & $-0.003_{* *}^{* *}$ & $(0.001)$ & $-0.003 \dagger$ & $(0.002)$ \\
\hline College classmates in region & $0.022 \dagger$ & $(0.012)$ & $0.028_{* *}^{* *}$ & $(0.005)$ & 0.019 & $(0.014)$ \\
\hline Other college classes in region & $-0.009_{* *}$ & $(0.007)$ & $-0.011_{* *}^{* *}$ & $(0.003)$ & $-0.006_{* *}$ & $(0.007)$ \\
\hline Work region & $5.426_{* *}^{* *}$ & $(0.041)$ & $1.313_{* *}^{* *}$ & $(0.047)$ & $2.806_{* *}^{* *}$ & $(0.081)$ \\
\hline Ln (region size) & $0.462^{*}$ & $(0.023)$ & 0.764 & $(0.012)$ & 0.708 & $(0.028)$ \\
\hline Fixed effects & \multicolumn{2}{|c|}{ Labor market } & \multicolumn{2}{|c|}{ Labor market } & \multicolumn{2}{|c|}{ Labor market } \\
\hline Pseudo $R^{2}$ & \multicolumn{2}{|c|}{0.81} & \multicolumn{2}{|c|}{0.44} & \multicolumn{2}{|c|}{0.58} \\
\hline Log-likelihood & \multicolumn{2}{|l|}{-7266} & \multicolumn{2}{|l|}{$-21,928$} & \multicolumn{2}{|l|}{-4252} \\
\hline Observations & \multicolumn{2}{|l|}{$1,479,629$} & \multicolumn{2}{|l|}{$1,493,908$} & \multicolumn{2}{|l|}{389,539} \\
\hline Individuals & \multicolumn{2}{|l|}{7500} & \multicolumn{2}{|l|}{7500} & \multicolumn{2}{|l|}{1939} \\
\hline
\end{tabular}

Robust standard errors in parentheses.

$\dagger$ Two-tailed significance level: $10 \%$.

* Two-tailed significance level: $5 \%$.

Two-tailed significance level: $1 \%$.

utility gained from an increase in their expected wage $\left(\Delta_{\text {wage }}\right)$ equal to the utility lost from being further from family and friends $\left(\Delta_{x}\right)$ :

$\beta_{\text {wage }} \Delta_{\text {wage }}=\beta_{x} \Delta_{x}$,

where $\beta_{\text {wage }}$ and $\beta_{x}$ are the conditional logit coefficients for, respectively, expected income and some other factor. For those variables specified in terms of logged distance, the tradeoff expected for a one unit increase in distance varies with distance. One intuitive way to interpret these coefficients considers the effect of a doubling in distance:

$\Delta_{\text {wage }}=\exp ^{\frac{\beta_{x} \ln 2}{\beta_{\text {wage }}}}$

Eq. (4) yields magnitudes in terms of percentage differences in income (because of the logging of expected income in the models), but one can convert them to average dollar equivalents by evaluating these percentage changes at the average expected wage. Table 3 reports these values.

Consider, for example, the results from model 3 (establishment closing sample). When comparing two potential jobs - one twenty miles from her home and the other forty miles away (i.e. double the distance) - an individual would prefer the closer job unless the more distant one paid at least $\$ 39,826$ more per year. Imagine that she also lived next door to her parents, then the more distant job would need to pay at least $\$ 52,579(=39,826+12,753)$ more for her to prefer it. These values are large. The average technical worker in Denmark earned roughly $\$ 69,000$ in 2006 , so the results imply that the typical individual might need to expect a near doubling in income to justify even a short move. Longer potential moves, which would entail more than a doubling of distance, would require even larger offsetting gains in expected income.

One might worry that these values seem too large. But of course if people placed less value on staying near to family and friends then one would expect much higher rates of geographic mobility (unless some other factor produced geographic inertia). Moreover, our estimates actually appear modest compared to those found in prior studies. For example, in one of the few other attempts to estimate the gains in income required to move - using average per capita wages in a state to proxy for expected income - Davies et al. (2001) calculated that the average American in 1996 would only consider another state equally attractive if it had per capita income of at least $\$ 170,820$ more than his or her current state of residence (more than six times the average per capita income).

Though the dollar equivalents help us to understand how individuals trade off income versus other factors, they do not provide direct intuition regarding the relative importance of various factors 
Table 3

Tradeoffs for annual income (US dollar equivalents).

\begin{tabular}{|c|c|c|c|}
\hline & Random sample & Employer change & Workplace closing \\
\hline Doubling distance to home & $\$ 157,672$ & $\$ 54,807$ & $\$ 39,826$ \\
\hline Doubling distance to parents & $\$ 415$ & $\$ 5,263$ & $\$ 12,753$ \\
\hline Doubling distance to siblings & $\$ 3,390$ & $\$ 2,389$ & $\$ 2,827$ \\
\hline Doubling distance to hometown & $\$ 16,730$ & $\$ 10,371$ & $-\$ 1,164$ \\
\hline Doubling distance to prior residences & $\$ 12,236$ & $\$ 12,739$ & $\$ 9,691$ \\
\hline One additional high school classmate & $\$ 901$ & $\$ 309$ & $\$ 340$ \\
\hline One additional college classmate & $\$ 3,362$ & $\$ 2,191$ & $\$ 1,299$ \\
\hline Average wage & $\$ 70,003$ & $\$ 69,168$ & $\$ 68,138$ \\
\hline
\end{tabular}

in the choice of where to work. To assess this relative importance, Table 4 reports the regression coefficients standardized by normalizing the independent variables to have means equal to zero and standard deviations of one (Menard, 2004). One can thus interpret these coefficients as indicating the change in the log odds of choosing a particular location given a one standard deviation increase in a particular economic or social factor.

Continuing to focus on the sample of individuals employed at workplaces that closed, the most important factor in choosing a new job is its proximity to the person's current residence. These places proxy for relationships to the people living there, but they also capture the potential real costs to moving residences. Proximity to parents weights next most heavily in the choice of work location, followed by the number of high school and college classmates in a region. Among all of the factors influencing the choice of locations, the potential for income gain actually ranks quite low.

\subsection{Random coefficients}

Our estimation approach involves two somewhat strong assumptions. First, the conditional logit assumes an equal probability of choosing each region, net of the observed characteristics-the independence of irrelevant alternatives (IIA) assumption. We assessed the importance of this assumption in two ways. We first ran tests of the sensitivity of the results to the removal of each of the regions from the choice set. Although these tests suggested that our models do not violate the IIA assumption, Monte Carlo simulations have found that such tests can generate false negatives even in large samples (Cheng and Long, 2007).

Next, we re-estimated models 1 through 3 using the mixed logit, with random coefficients for each of the independent variables (but with fixed effects for the labor markets). Not only does the

Table 4

Standardized coefficient estimates.

\begin{tabular}{|c|c|c|c|}
\hline & Random sample & Employer change & Workplace closing \\
\hline Distance to home & -1.05 & -1.07 & -.935 \\
\hline Distance to parents & -.004 & -.168 & -.444 \\
\hline High school classmates & .358 & .234 & .383 \\
\hline College classmates & .303 & .415 & .293 \\
\hline Distance to prior residences & -.104 & -.309 & -.260 \\
\hline Expected wage & .069 & .130 & .145 \\
\hline Distance to siblings & -.034 & -.081 & -.106 \\
\hline Distance to hometown & .173 & -.329 & .043 \\
\hline
\end{tabular}

Table 5

Mixed logit estimates of location choice.

\begin{tabular}{|c|c|c|c|c|c|c|c|c|c|c|c|c|}
\hline & \multicolumn{4}{|c|}{$\begin{array}{l}(4) \\
\text { Random sample }\end{array}$} & \multicolumn{4}{|c|}{$\begin{array}{l}\text { (5) } \\
\text { Employer change }\end{array}$} & \multicolumn{4}{|c|}{$\begin{array}{l}(6) \\
\text { Workplace closings }\end{array}$} \\
\hline & Mean & & SD & & Mean & & SD & & Mean & & SD & \\
\hline Expected Ln (income) & $0.825^{* *}$ & $(0.257)$ & -0.121 & $(0.424)$ & $0.895^{* * *}$ & $(0.120)$ & 0.005 & $(0.225)$ & $1.249^{* * *}$ & $(0.288)$ & 0.415 & $(0.455)$ \\
\hline Ln (distance to home) & $-1.001^{* *}$ & $(0.024)$ & 0.012 & $(0.049)$ & $-0.854_{* *}^{* *}$ & $(0.015)$ & -0.005 & $(0.039)$ & $-0.861_{* *}^{* *}$ & $(0.033)$ & -0.023 & $(0.076)$ \\
\hline Ln (distance to parents) & -0.119 & $(0.145)$ & -0.174 & $(0.314)$ & $-0.110^{* *}$ & $(0.025)$ & $0.129^{\dagger}$ & $(0.068)$ & $-0.326^{* *}$ & $(0.056)$ & 0.007 & $(0.104)$ \\
\hline Ln (distance to siblings) & -0.152 & $(0.120)$ & -0.206 & $(0.273)$ & $-0.050_{* *}^{*}$ & $(0.021)$ & -0.003 & $(0.189)$ & -0.079 & $(0.049)$ & -0.091 & $(0.216)$ \\
\hline Ln (distance to hometown) & -0.136 & $(0.136)$ & -0.073 & $(0.238)$ & $-0.189_{* * *}^{* *}$ & $(0.024)$ & -0.020 & $(0.006)$ & 0.008 & $(0.085)$ & 0.062 & $(0.133)$ \\
\hline Ln (distance to prior residences) & $-0.174 * *$ & $(0.141)$ & -0.011 & $(0.171)$ & $-0.233^{* *}$ & $(0.032)$ & -0.007 & $(0.049)$ & $-0.163 \dagger$ & $(0.093)$ & 0.046 & $(0.211)$ \\
\hline High school classmates in region & $0.014_{* *}^{* *}$ & $(0.005)$ & -0.002 & $(0.003)$ & $0.011_{* *}^{* *}$ & $(0.003)$ & $-0.008^{* *}$ & $(0.002)$ & 0.008 & $(0.006)$ & $0.006^{* *}$ & $(0.002)$ \\
\hline Other high school classes in region & $-0.008_{*}^{* *}$ & $(0.003)$ & $-0.003^{* *}$ & $(0.001)$ & $-0.008_{* *}^{* *}$ & $(0.002)$ & $-0.000_{* *}$ & $(0.002)$ & $-0.005_{*}$ & $(0.003)$ & -0.001 & $(0.001)$ \\
\hline College classmates in region & $0.024^{*}$ & $(0.013)$ & 0.004 & $(0.007)$ & $0.040_{* *}^{* *}$ & $(0.006)$ & $-0.017_{*}^{*}$ & $(0.006)$ & $0.030^{*}$ & $(0.014)$ & $-0.011_{* *}$ & $(0.013)$ \\
\hline Other college classes in region & $-0.006_{* *}$ & $(0.007)$ & $-0.004_{* *}$ & $(0.007)$ & $-0.015_{* * *}^{* *}$ & $(0.003)$ & $-0.007_{* *}^{*}$ & $(0.003)$ & $-0.006_{* *}$ & $(0.008)$ & $-0.013_{* * *}^{* *}$ & $(0.005)$ \\
\hline Work region & $11.718_{* *}^{* *}$ & $(0.692)$ & $8.290^{* *}$ & $(0.680)$ & $0.618_{* *}^{* *}$ & $(0.072)$ & $2.600^{* *}$ & $(0.105)$ & $2.792_{* *}^{* *}$ & $(0.140)$ & $4.096^{* *}$ & $(0.032)$ \\
\hline Ln (region size) & 0.789 & $(0.028)$ & 0.014 & $(0.033)$ & $0.828^{*}$ & $(0.013)$ & -0.036 & $(0.036)$ & $0.848^{*}$ & $(0.031)$ & -0.021 & $(0.057)$ \\
\hline Fixed effects & \multicolumn{4}{|c|}{ Labor market } & \multicolumn{4}{|c|}{ Labor market } & \multicolumn{4}{|c|}{ Labor market } \\
\hline Log-likelihood & \multicolumn{4}{|c|}{-6894} & \multicolumn{4}{|c|}{$-21,764$} & \multicolumn{4}{|c|}{-4192} \\
\hline Observations & \multicolumn{4}{|l|}{$1,479,629$} & \multicolumn{4}{|l|}{$1,493,908$} & \multicolumn{4}{|l|}{389,539} \\
\hline Individuals & \multicolumn{4}{|l|}{7500} & \multicolumn{4}{|l|}{7500} & \multicolumn{4}{|l|}{1939} \\
\hline
\end{tabular}

Robust standard errors in parentheses.

+ Two-tailed significance level: $10 \%$.

* Two-tailed significance level: $5 \%$.

** Two-tailed significance level: $1 \%$. 
mixed logit not assume IIA, but also it allows us to explore whether the weights appear to differ substantially across individuals (Train, 2003). We report these estimates in Table 5. Since the mixed logit produced similar average coefficients and the coefficients generally varied little across individuals (except for the weighting of high school classmates and the region of prior employment), we have reasonable confidence that the IIA assumption does not prove problematic in these models.

\subsection{Functional form}

The second assumption concerns the functional form of the relationship between utility and the distances of relatives, prior residences and other social factors. To explore this issue further, we estimated a set of models where we splined each distance measure into three pieces (of equal logged intervals), allowing the effects of distance to vary across these ranges. Rather than report many, many coefficients, Fig. 6 depicts these estimated effects graphically and compares them to the predicted values that one would obtain from the estimates using the coefficient values from the logged functional form. The solid lines plot the predicted values using logged distances while the dotted lines depict the splined estimates. The first column displays the results for the random sample, the second for the sample of job changers and the third for those forced to change jobs because of a workplace closing. Beginning with the first row, distance to home, one can see that the splined results follow a similar slope to the logged distance results. It appears, however, that the logged estimates may overstate the disutility associated with short increases in distance but understate that associated with longer distances. The distance to parents and to past places lived, rows two and five respectively, show similar patterns. Although the splined estimates appear to deviate substantially from the logged estimates for distance to siblings and distance to hometown (rows three and four), especially in the random sample, in neither of these cases did the logged variable have a significant coefficient.

\subsection{Age}

Although the conditioning in the McFadden choice model essentially purges the attributes of individuals from the estimates, one can nonetheless examine whether individuals differ in the weights that they assign to various factors either through interaction effects or by estimating the models on subsamples. Here, we thought it interesting to explore individual-level variation on two dimensions: age and marital status. Beginning with age, past studies have found that individuals' preferences shift as they mature. (Chen and Rosenthal, 2008), for example, found that younger individuals, compared to older ones, placed greater weights on potential earnings relative to regional amenities when considering where to locate. One might therefore expect a similar pattern to changes with age in the relative weighting of income versus family and friends.

Table 6 reports estimates, within age groups, using the sample of those employed at workplaces that closed in 2004 or 2005. We divided these individuals into three groups: those 30 and under, those between the ages of 31 and 36 inclusive, and those between the ages of 37 and 42 inclusive. Interestingly, in contrast to Chen and Rosenthal (2008), we find that scientists and engineers, as they mature, place more importance on income and less on proximity to prior residences and to college friends relative to other factors. Either technical workers, or Danes, exhibit a different

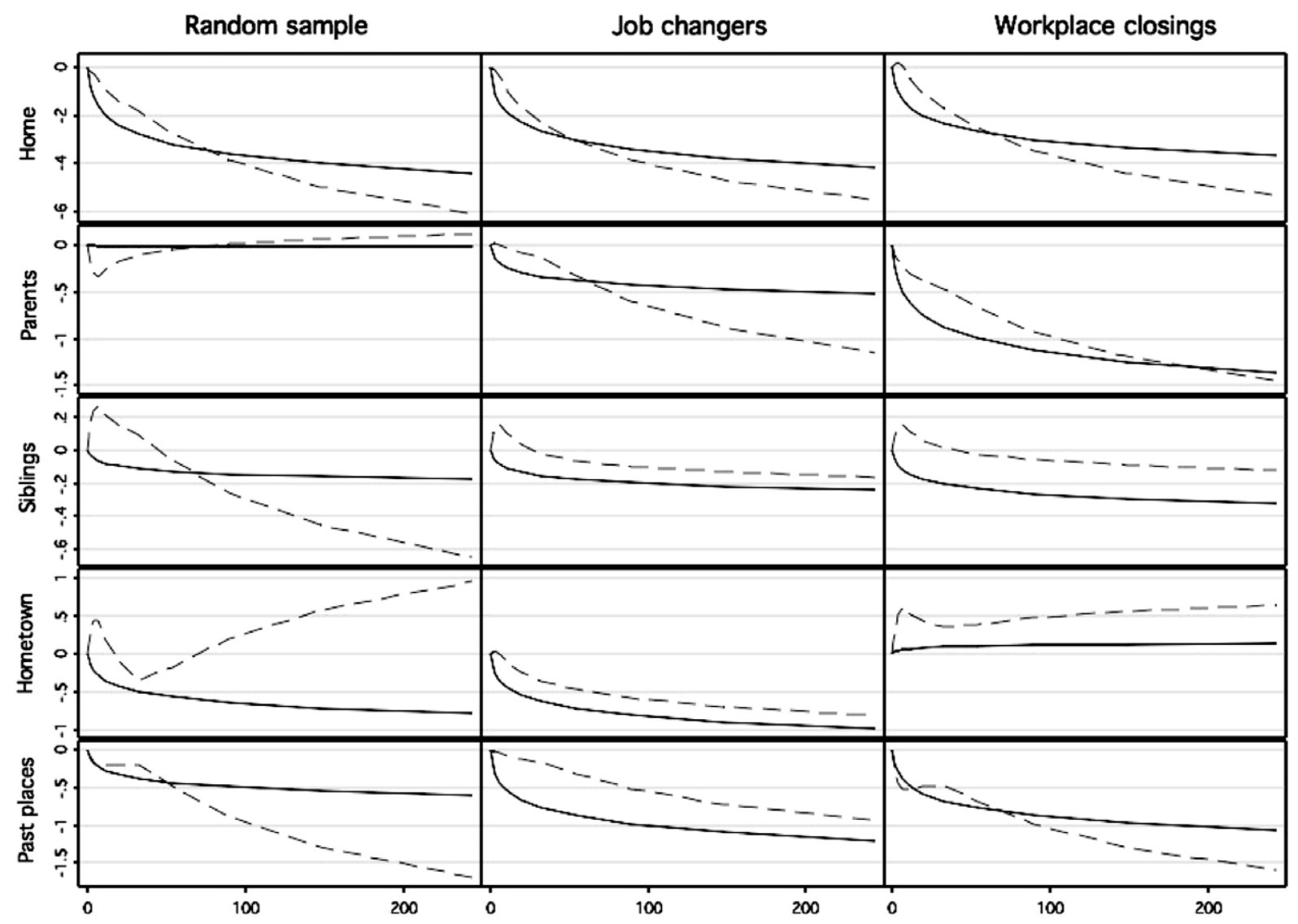

Fig. 6. Coefficient estimates for splined versus logged distance measures. 
Table 6

Conditional logit estimates of location choice by age.

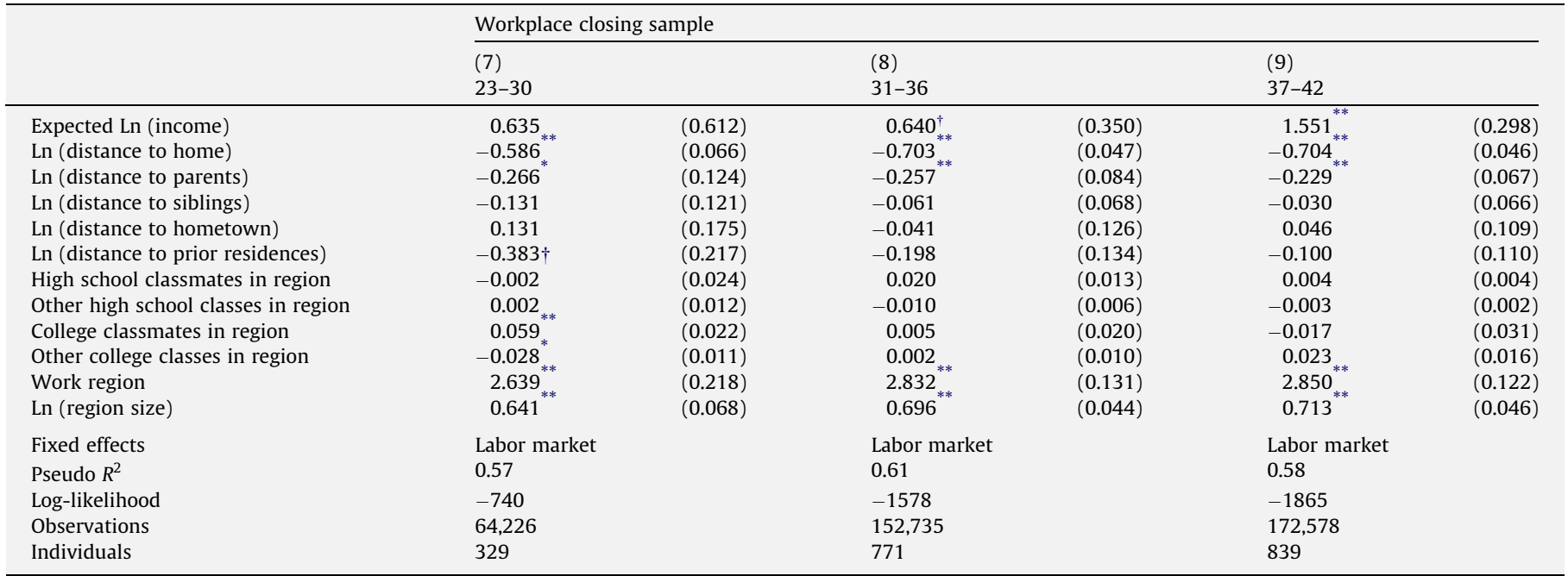

Robust standard errors in parentheses.

$\dagger$ Two-tailed significance level: $10 \%$.

* Two-tailed significance level: $5 \%$.

Two-tailed significance level: $1 \%$.

evolution of preferences over time from the average American, or individuals tradeoff proximity to family and friends in a different way from amenities.

\subsection{Power couples}

Finally, we explored the issue of couples. Costa and Kahn (2000) have argued that power couples - those involving two professionals - have become increasingly concentrated in cities as these couples struggle to cope with the constraints of dual careers. That thesis suggests that, relative to other economic and social factors, power couples should place greater emphasis on locating in urban areas and that they may assign less value to being near to family and friends.

Roughly $8 \%$ of scientists and engineers in Denmark had technical worker spouses $(N=6470)$. This pool did not provide enough cases for us to further restrict this sample, either to those changing jobs or to those employed at plants that closed, but it did allow us to estimate weights within this subgroup. Table 7 reports the results of a model where we limited the analysis to these two-technical-worker couples.

Because this group comprises the population of these couples, the random sample offers the most appropriate comparison. The estimates from technical power couples differ from those derived from the random sample in three respects. First, relative to income and other social factors, these couples placed greater weight on locating near to their parents, perhaps because they value more highly the potential child care support that family can offer. They also assigned higher relative importance to remaining close to past regions in which they had lived and to regions in which they had college classmates.

Interestingly, these couples did not exhibit a stronger relative preference for areas with larger populations. ${ }^{10}$ That result appears inconsistent with the Costa and Kahn (2000) conjecture. Of course, it is possible that the difference reflects the fact that we focus on scientists and engineers while Costa and Kahn (2000) consider all those with college degrees. It is also possible that power couples have a

\footnotetext{
${ }^{10}$ One might worry that the labor market fixed effects absorb much of the interesting variation in where couples versus singles want to locate. That result, however, holds even in models that do not include labor market fixed effects.
}

Table 7

Conditional logit estimates of location choice for couples.

\begin{tabular}{lcc}
\hline & \multicolumn{1}{l}{$(10)$} & \\
& Couples & \\
\hline Expected Ln (income) & $0.790^{* * *}$ & $(0.154)$ \\
Ln (distance to home) & $-0.662^{* *}$ & $(0.039)$ \\
Ln (distance to parents) & $-0.136^{* *}$ & $(0.048)$ \\
Ln (distance to siblings) & $-0.237^{* *}{ }^{* *}$ & $(0.045$ \\
Ln (distance to hometown) & $-0.301^{* *}$ & $(0.044)$ \\
Ln (distance to prior residences) & $0^{0.004}$ & $(0.071)$ \\
High school classmates in region & $-0.004^{\dagger}$ & $(0.005)$ \\
Other high school classes in region & $0.051^{* *}$ & $(0.012)$ \\
College classmates in region & $-0.025^{* *}$ & $(0.006)$ \\
Other college classes in region & $5.380^{* *}$ & $(0.046)$ \\
Work region & $0.499^{* *}$ & $(0.025)$ \\
Ln (region size) & Labor market & \\
Fixed effects & 0.83 & \\
Pseudo $R^{2}$ & -5550 & \\
Log-likelihood & $1,192,149$ & \\
Observations & 6470 & \\
Individuals & & \\
\hline
\end{tabular}

Robust standard errors in parentheses

$\dagger$ Two-tailed significance level: $10 \%$.

Two-tailed significance level: $5 \%$.

Two-tailed significance level: $1 \%$.

different dynamic in Denmark. But it nonetheless seems probable that some other mechanism may account for the concentration of power couples in cities. For example, highly educated individuals may move to cities before they get married, perhaps in the expectation that they will find appropriate partners there. Or, the highly educated might move to cities for their own individual reasons. Even a random marriage matching of individuals within regions would then lead to a higher concentration of power couples in these urban areas. Although answering this question falls beyond the scope of this paper, our results nonetheless suggest the need for further exploration of this phenomenon.

\section{Discussion}

Explanations for the relative economic prosperity of some regions relative to others have often pointed to the concentration 
of scientists and engineers as an important factor. These individuals represent the engines of innovation. The benefits of their innovations may moreover remain rooted in the regions in which those individuals live and work for a number of reasons-they may require complementary assets, involve a large degree of tacit knowledge or fall under the protection of intellectual property rights. Indeed, Rosenthal and Strange (2008) have estimated that these spillovers extend no more than a few miles.

Both social scientists and policy makers have thus been quite interested in the movements of these highly-educated individuals, particularly across international borders. Politicians and bureaucrats have promoted immigration policies favorable to technical workers. Social scientists, meanwhile, have bemoaned the potential brain drain effect of these migrations on the regions that these individuals leave.

We nevertheless have limited understanding to date of why technical workers move and of where they move within countries. We offer early evidence on both of these questions by exploiting an unusually rich data source, covering all residents of Denmark, and by developing a methodology for estimating expected incomes in each region specific to the individual, on the basis of regional differences in the returns to education in specific subjects. We have further refined prior research by identifying a sample of individuals who chose to change jobs for reasons exogenous to their own preferences and abilities, and consequently where selection bias does not plague the results: those employed at workplaces that closed.

Our results reveal that Danish technical workers place very high weights on social factors when considering where to work. From most to least important, those educated as scientists and engineers care about proximity to their current residence, proximity to their parents, the number of high school classmates in a region, the number of college classmates in a region, proximity to past places they have lived, and income. For the typical Danish scientist, engineer or medical worker, social factors swamp economic considerations in their choices of where to work.

Although we interpret these findings as primarily reflecting individuals' preferences for being near to family and friends, two other factors might contribute to our results. First, family and friends may serve as sources of information on job opportunities and the prevailing wages in other regions. Individuals therefore may move to the regions in which their family and friends live because they have the best information about the available jobs in those regions. Second, because individuals know with relative certainty the locations of their loved ones but not necessarily the prevailing wages in all regions, their weights may in part reflect a discounting of this more noisy information. Both of these factors could potentially lead us to to overestimate the importance of family and friends relative to expected income in location choice.

Though we believe that the unusual quality of the data justifies focusing on the Danish case, one might worry that our results would not extrapolate to other countries, particularly ones such as the United States where people have more recent roots in regions. Two facts, however, suggest otherwise. First, within geographic units of similar size - within state mobility in the United States - Danes appear as mobile as Americans (if not more so). Second, estimates of how Americans trade off gains in expected income against moving have found even lower sensitivity to expected income (Davies et al., 2001; Kennan and Walker, 2003; Bayer and Jussen, 2006), also hinting that Americans may value family and friends more highly on average and therefore exhibit less mobility than Danes.

The fact that individuals weight social factors much more heavily than economic ones in deciding where to work and live nonetheless has important implications for both research and public policy. Most immediately, it suggests that labor markets operate at quite local levels. Since even relatively large differences in income are insufficient to entice most individuals to move, the set of jobs realistically of interest to the typical individual would include only those in a relatively restricted geographic radius from his or her home. It further suggests that even very large differences in wages across regions can persist for long periods of time. If individuals rarely move to higher paying regions to arbitrage these wage differentials, then the primary force for equilibration comes from companies moving to places with lower wages. But even from the side of the employer, investments in physical plant and the training of existing employees - who themselves would prefer not to move - strongly anchor existing firms to their current locations. From a policy perspective, it suggests that regions would more usefully invest in assisting their residents in the acquisition of human capital than in attempting to lure highly productive individuals away from other places.

It also points to an alternative explanation for the geographic clustering of industries. Traditional explanations for this pattern have focused either on the location of inputs or on agglomeration externalities. More recent empirical research has nonetheless noted that spin-outs - firms started by individuals with experience at an industry incumbent - play a particularly important role in the geographic concentration of industries (Klepper, this issue). Though some have interpreted this fact as further evidence for agglomeration externalities, another possibility exists: Even if these entrepreneurs had much to gain financially by locating their ventures far from their prior employers, they might willingly forgo these gains in exchange for the satisfaction that they derive from remaining close to family and friends (Sorenson and Audia, 2000; Dahl and Sorenson, 2009).

\section{References}

Bayer, Christian, Jussen, Falko, 2006. A generalized options approach to aggregate migration with an application to US federal states. Working Paper, University of Dortmund.

Bhagwati, Jagdish N., Hamada, Koichi, 1974. The brain drain, international integration of markets for professionals and unemployment. Journal of Development Economics 1, 19-42.

Chen, Yong, Rosenthal, Stuart S., 2008. Local amenities and life cycle migration: do people move for jobs or fun? Journal of Urban Economics 65, 519537.

Cheng, Simon, Long, J. Scott, 2007. Testing for IIA in the multinomial logit model Sociological Methods and Research 35, 583-599.

Combes, Pierre-Philippe, Duranton, Gilles, Gobillon, Laurent, 2008. Spatial wage disparities: sorting matters! Journal of Urban Economics 63, 723-742.

Costa, Dora L., Kahn, Matthew E., 2000. Power couples: changes in the locational choice of the college educated, 1940-1990. Quarterly Journal of Economics 115, 1287-1315.

Coulson, N. Edward, Fisher, Lynn, 2009. Housing tenure and labor market impacts: the search goes on. Journal of Urban Economics 65, 252-264.

Dahl, Michael S., Sorenson, Olav, 2008. The social attachment to place. Working Paper, University of Aalborg.

Dahl, Michael S., Sorenson, Olav, 2009. The embedded entrepreneur. European Management Review 6, 172-181.

Davies, Paul S., Greenwood, Michael J., Li, Haizheng, 2001. A conditional logit approach to US state-to-state migration. Journal of Regional Science 41, 337360.

Dumont, Jean-Christophe, Lemaitre, Georges, 2005. Counting immigrants and expatriates in OECD countries: a new perspective. OECD Social Employment and Migration Working Papers, No. 25.

Figueiredo, Octavio, Guimaraes, Paulo, Woodward, Douglas, 2002. Home-field advantage: location decisions of Portuguese entrepreneurs. Journal of Urban Economics 52, 341-361.

Galor, Oded, Tsiddon, Daniel, 1997. The distribution of human capital and economic growth. Journal of Economic Growth 2, 93-124.

Glaeser, Edward L., Kolko, Jed, Saiz, Albert, 2001. Consumer city. Journal of Economic Geography 1, 27-50.

Gmelch, George, 1980. Return migration. Annual Review of Anthropology 9, 135159.

Kennan, John, Walker, James R., 2003. The effect of expected income on individual migration decisions. NBER Working Paper 9585.

Klepper, Steven, this issue. The origin and growth of industry clusters: the making of Silicon Valley and Detroit. Journal of Urban Economics 67. doi:10.1016/ j.jue.2009.09.004 
Levin, Sharon G., Stephan, Paula E., 1999. Are the foreign born a source of strength for US science? Science 285, 1213-1214.

McFadden, Daniel, 1974. Conditional logit analysis of qualitative choice behavior. In: Zarembka, P. (Ed.), Frontiers of Econometrics. Academic Press, New York, pp. 105-142.

Medawar, Jean, Pyke, David, 2001. Hitler's Gift: The True Story of the Scientists Expelled by the Nazi Regime. Arcade Publishing, New York.

Menard, Scott, 2004. Six approaches to calculating standardized logistic regression coefficients. American Statistician 58, 218-223.

Romer, Paul M., 1986. Increasing returns and long-run growth. Journal of Political Economy 94, 1002-1037.

Rosenthal, Stuart S., Strange, William C., 2008. The attentuation of human capital externalities. Journal of Urban Economics 64, 373-389.

Scott, Darren M., Coomes, Paul A., Izyumov, Alexei I., 2005. The location choice of employment-based immigrants among US metro areas. Journal of Regional Science 45, 113-145.
Sjaastad, Larry A., 1962. The costs and returns of human migration. Journal of Political Economy 70, 80-93.

Sorensen, Jesper B., Sorenson, Olav, 2007. Corporate demography and income inequality. American Sociological Review 72, 766-783.

Sorenson, Olav, Audia, Pino G. 2000. The social structure of entrepreneurial activity: geographic concentration of footwear production in the United States, 19401989. American Journal of Sociology 106, 424-462.

Stephan, Paula E., Levin, Sharon G., 2001. Exceptional contributions to US science by foreign-born and foreign-educated. Population Research and Policy Review 20, 59-79.

Todaro, Michael P., 1969. A model of labor migration and urban unemployment in less developed countries. American Economic Review 59, 138-148.

Train, Kenneth, 2003. Discrete Choice Methods with Simulation. Cambridge University Press

Vroom, Victor H., 1964. Work and Motivation. Wiley, New York. 